\title{
An integrated approach to evaluate suppliers in a sustainable supply chain
}

\author{
Seyed Hamid Hashemi Petrudia ${ }^{{ }^{*}}$, Mehdi Abdi ${ }^{\mathrm{a}}$ and Mark Goh ${ }^{\mathrm{b}}$
}

${ }^{a}$ Department of Industrial Management, Faculty of Management, University of Tehran, Tehran, Iran ${ }^{b}$ NUS Business School, National University of Singapore, Singapore

\begin{tabular}{l}
\hline C H R O N I C L E \\
\hline Article history: \\
Received March18, 2017 \\
Accepted November 202017 \\
Available online \\
December 142017 \\
\hline Keywords: \\
Supply chain management \\
Sustainable supplier selection \\
Multi-criteria decision making \\
(MCDM) \\
Fuzzy theory \\
ANP \\
TOPSIS
\end{tabular}

\section{Introduction}

Increasing concerns over environmental, social and corporate responsibilities from customers, NGOs, and law enforcements have attracted scholars and industry practitioners to the concept of sustainable supply chain management (Govindan et al., 2013). Such responsibilities serve to drive organizational initiatives and legislations in sustainability (Dao et al., 2011). Seuring and Müller (2008) mentioned that the pressures from the internal and external drivers (especially from customers and government) trigger the awareness of sustainability in a supply chain, since firms tend to pass such pressures to new suppliers. Focal firms that are nearest to the marketplace in a supply chain are held responsible for the performance and the effect of their partners on environment and society. Choosing suppliers who are capable of integrating their competencies and capabilities with those of the focal firm are thus crucial for securing competitive advantage (Lin, 2012). The adoption of sustainable strategies has a higher chance of success when the suppliers are also aligned to these strategies (Tang \& Zhou, 2012).

* Corresponding author Tel.: +989128909196; fax: +982188006477

E-mail address: s.hamidhashemi@ut.ac.ir (S. H. Hashemi Petrudi)

(C) 2018 by the authors; licensee Growing Science, Canada doi: $10.5267 /$ j.uscm.2017.12.003 
Supplier selection typically utilizes the output of supplier performance assessment scores to identify the appropriate suppliers. Traditional sourcing decisions often focus on economic criteria in practice and fail to consider other environmental and social criteria (Chopra \& Meindl, 2007). Increasing concerns about environmental and social issues in organizations requires a sustainability approach to supply chain relationships (Ciliberti et al., 2008; Seuring et al., 2008). There are various sets of indicators to measure sustainability (Joung et al., 2013; Kausar et al., 2017). These indicators are usually not included in operational decisions, but become necessary as the notion of corporate social responsibility is nurtured within an organization (Bai \& Sarkis, 2010). The strategic nature of sourcing decisions necessitates the consideration of tangible and intangible criteria and the application of elaborated methods for supplier selection. There are many instances of developing integrated methods such as mathematical programming, Analytic Hierarchy Process (AHP), ANP, and fuzzy sets for supplier selection (Wu \& Pagell, 2011; Rabbani et al., 2018). This paper seeks to (i) identify and select the important criteria and their interrelationships in the three dimensions of sustainability, and (ii) rank the suppliers according to the elicited criteria. To the best of our knowledge, there is only few studies on the supplier selection model involving multiple suppliers, multiple items and according to supplier performance on all the three dimensions of sustainability which considers the interrelationships among the sustainability criteria. The proposed approach contributes to the literature on sustainable supplier management as follows. First, we combine the ISM, FPP, and FDEMATEL to construct the supermatrix to find the weights of the sustainability criteria. Next, FTOPSIS is employed to rank the suppliers based on the sustainability criteria. To the best of our knowledge, this is the first time to propose an integrated sustainable supplier selection model by combining these methods logically. The contributions of the paper are more discussed in section 2.4.

The rest of the paper is organized as follows. In Section 2, the literature on sustainable supplier selection is reviewed. Section 3 explains the proposed methodology and then, as described in Section 4, applied to an actual case study. Section 5 provides some concluding remarks and suggestions for future studies.

\section{Literature Review}

\subsection{Sustainable supply chain management}

Elkington (1997) introduced the term 'triple bottom-line' (TBL) in sustainability as a framework for measuring the effect of corporate performance on economy, society and environment. This concept is applied in sustainable supply chain management (SSCM) to align corporate economic objectives with the environmental and social responsibilities as a long-term perspective for suppliers (Ciliberti et al., 2011). In SSCM, the decisions on sourcing, product design, and manufacturing processes are taken to maximize profitability while minimizing the environmental side effects and maximizing social wellbeing (Hassini et al., 2012). The importance of SSCM and supplier selection as one of its major components have grown over the years (Azadi et al., 2015) and there are many instances of SSCM application in industry in the literature: packaging (Azadnia et al., 2015), white goods (Büyüközkan \& Çifçi, 2012), agricultural equipment (Dou et al., 2014), retail (Erol et al., 2011), textile (Govindan et al., 2013), automotive (Gupta et al., 2016; Hashemi et al., 2015; Kannan et al., 2013; Olugu \& Wong, 2012), plastics (Azadi et al., 2015; Kannan et al., 2015), electronics (Kuo et al., 2010; et al., 2009; Lin \& Tseng, 2016; Tseng \& Chiu, 2013), and gas (Mehregan et al., 2014; Asadi \& Sadjadi, 2017).

\subsection{Sustainable supplier selection criteria}

\subsubsection{Economic criteria}

According to Mefford (2011), sustainable supply chain leads to higher profits through three main channels of effect: (i) customers who prefer to buy from firms with a sustainable supply chain (which creates an opportunity for more sales or charging higher prices), (ii) the result of adopting lean 
principles (e.g., the ability to attract workers with increased skills and motivation which then leads to higher quality and productivity), and (iii) the reduction of financial risks due to fewer claims and lawsuits from internal or external entities. Economic criteria such as quality, cost, delivery, and service were the themes in the traditional approach to supplier evaluation (Amindoust et al., 2012). Cost was considered as the main criterion in early studies in this field in the 1970s (Kannan et al., 2013). In fact, the literature began with a cost and resource-based approach to supplier evaluation (Hashemi et al., 2015). As Siegel (2009) argued, a sustainable supply chain practice is acceptable only if it enhances profitability or shareholder wealth. However, the TBL approach requires volunteering in environmental and social activities along with improving the economic performance of firms (Govindan et al., 2013). Table 1 summarizes economic criteria in supplier evaluation literature.

Table 1

Literature on economic criteria in supplier selection

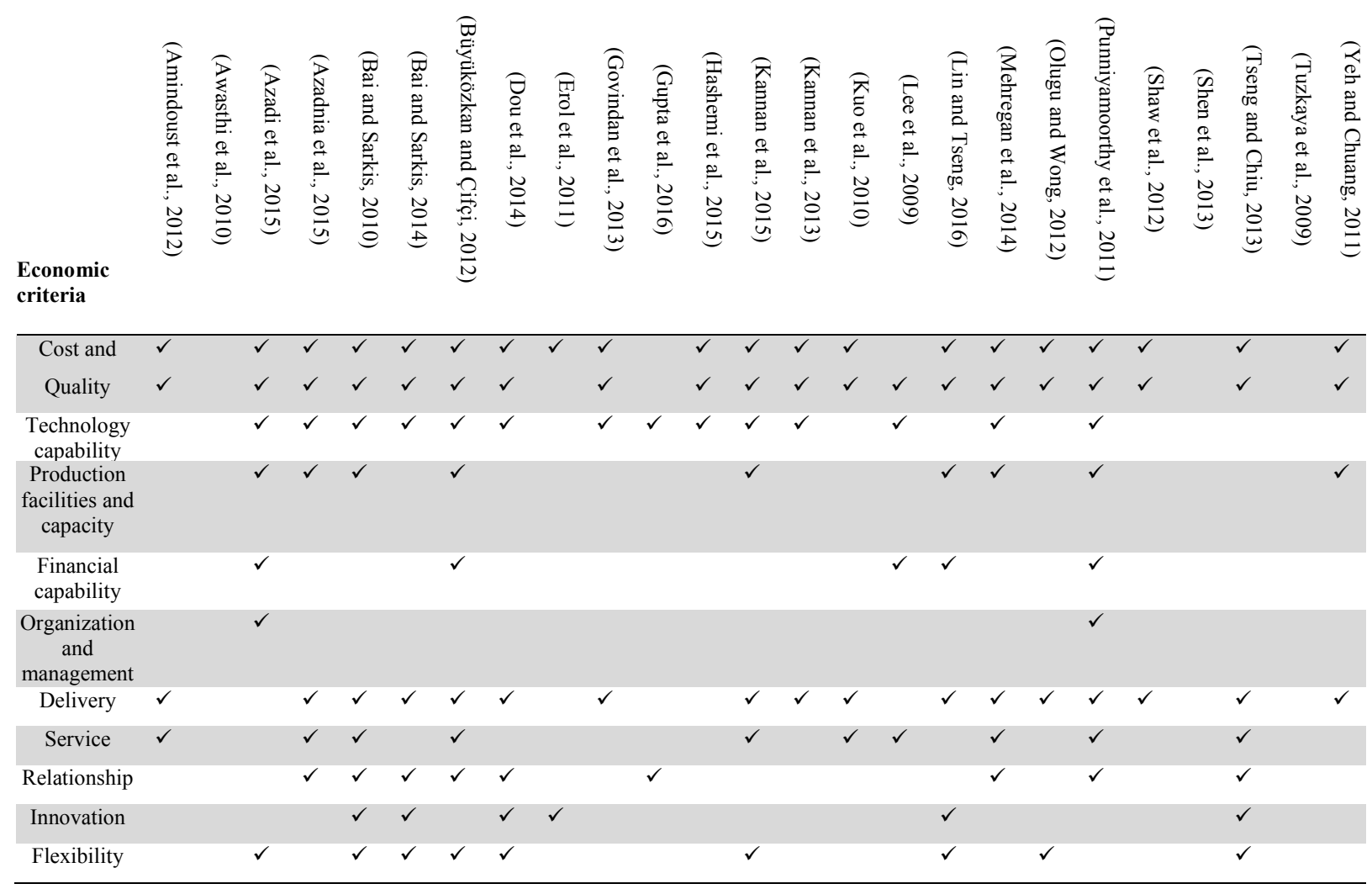

\subsubsection{Environmental criteria}

SSCM extends green supply chain management (GSCM), as SSCM integrates social and economic factors to the environmental factors considered in GSCM (Ahi \& Searcy, 2013). GSCM seeks environmental improvements in the purchase of raw materials, manufacturing, order allocation, transport efficiency, storage time, importing and disposing of products (Kannan et al., 2015; Yeh \& Chuang, 2011). The aim of GSCM is to reduce environmental pollution from upstream to downstream (Kuo et al., 2010), thus decreasing the environmental and legal risks for a firm (Shen et al., 2013). A firm's environmental performance is affected by its suppliers' environmental performance and selecting green suppliers is a strategic decision to be more competitive in a global market (Kannan et al., 2013). Suppliers must therefore be included in environmentally-friendly practices for purchasing and materials management, starting from supplier design for the environment (Lee et al., 2009). Table 2 lists environmental criteria in supplier selection literature. 
Table 2

Literature on environmental criteria in supplier selection

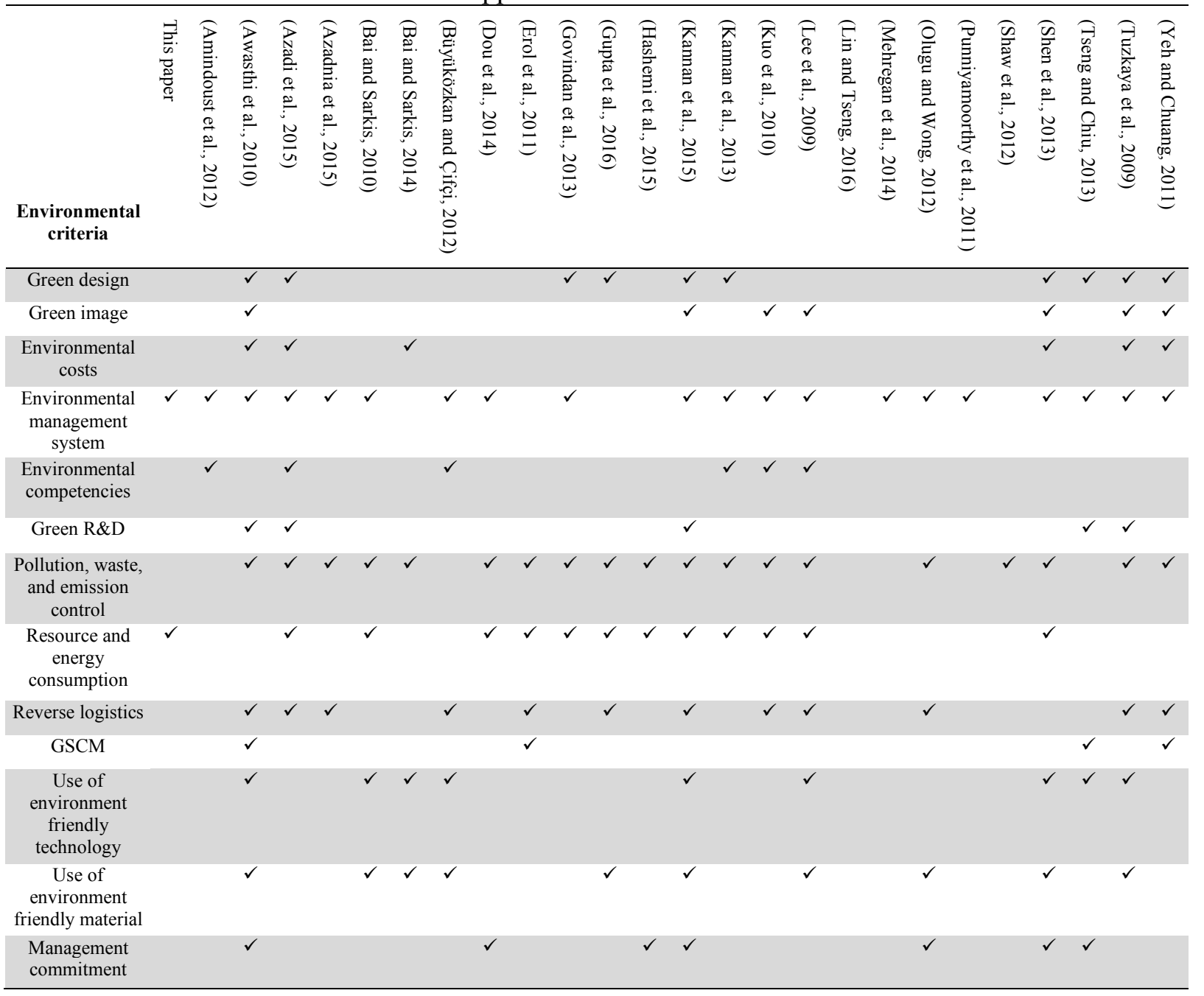

\subsubsection{Social criteria}

The understanding of sustainable development is fragmented and mostly one-dimension, i.e., environmentally based (Erol et al., 2011). It is necessary that the dual aspects of economic and environmental criteria in supplier selection be expanded even further to include a social criterion. Recently, due to increased pressure from government and stakeholders to incorporate social responsibility in supply chain activities, some studies have tried to incorporate the social responsibility dimension in the supplier selection problem (Azadnia et al., 2015). In response to customer and shareholder concerns on corporate social responsibility (CSR), many buying firms are implementing programs with their supply chains, which are aimed at ensuring that their suppliers act in a socially responsible way in respect to labour practices and the environment (Shen et al., 2013). SSCM suggests that proactive sustainability yields competitiveness, economic benefits, and better CSR (Lin \& Tseng, 2016). Table 3 lists social criteria in supplier selection literature. 
Table 3

Literature on social criteria in supplier selection

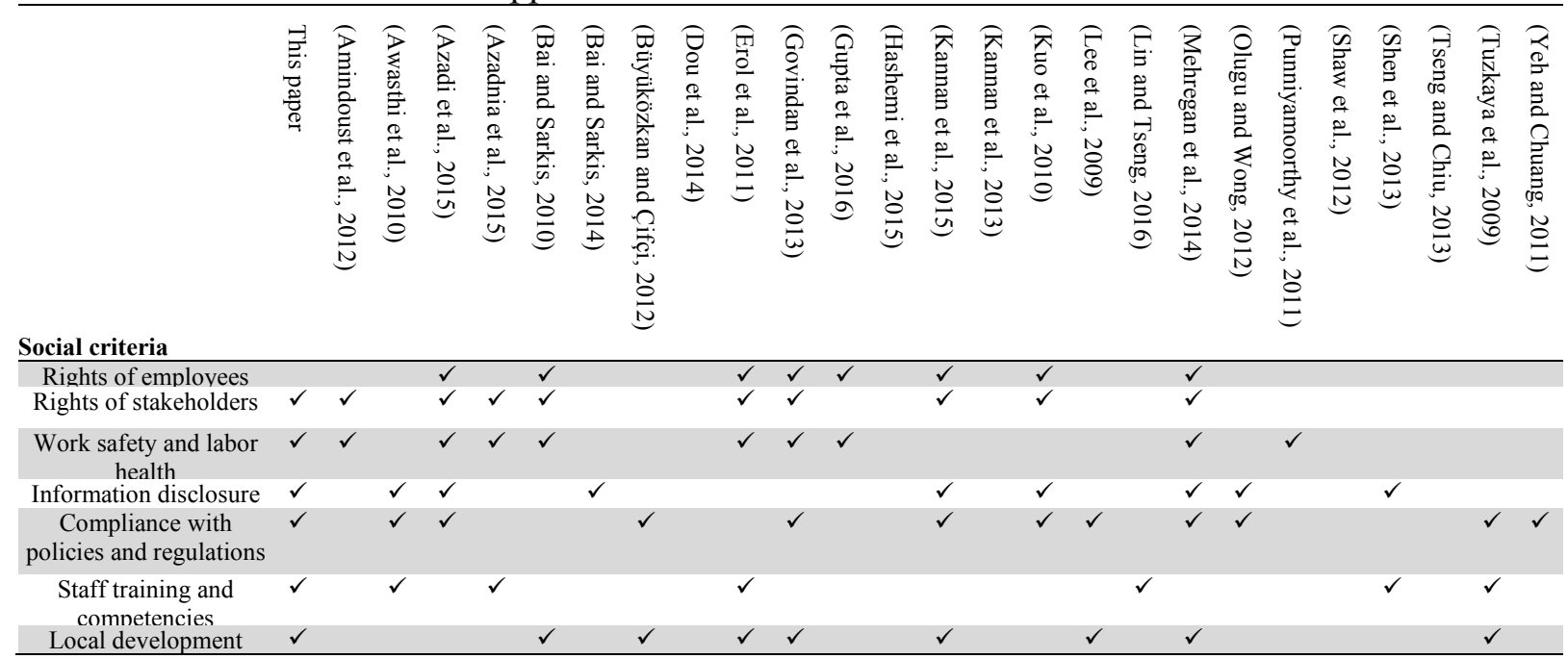

\subsection{Sustainable supplier selection methods}

As mentioned, due to the possible changes in contract terms in the projects, the supplier selection problem has an element of uncertainty. The literature reports several approaches to deal with the uncertainty in sustainable supplier selection. Büyüközkan and Çifçi (2012) applied incomplete fuzzy preferences which can deal with the uncertainty of the decision makers and missing data. Bai and Sarkis (2010) used grey-based rough-set theory for discrete data and incomplete information and grey relational analysis to analyse the uncertain relationships between the factors. Tseng and Chiu (2013) combined fuzzy set theory and grey relational analysis to rank the suppliers. Chai et al. (2013), in reviewing supplier selection methods, found that the techniques used in the uncertain supplier selection literature are categorized into three classes: MCDM, mathematical programming, and artificial intelligence. Table 4 summarizes the applied methodologies in supplier selection.

Table 4

Literature on applied methodologies in supplier selection

\begin{tabular}{|c|c|c|c|c|c|c|c|c|c|c|c|c|c|c|c|c|c|c|c|c|c|c|c|c|c|c|c|}
\hline 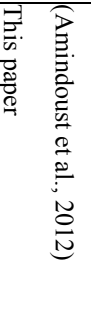 & 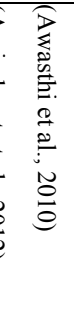 & 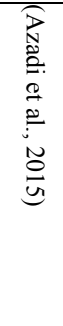 & 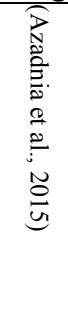 & 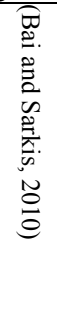 & 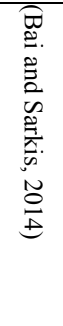 & 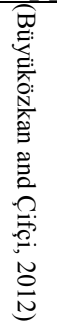 & 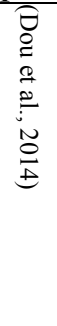 & 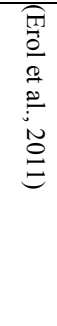 & 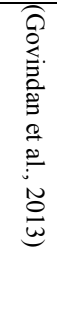 & 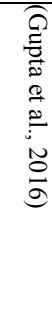 & 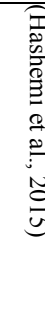 & & 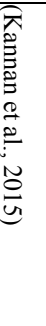 & 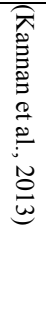 & 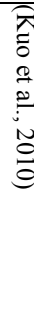 & & 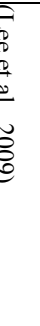 & 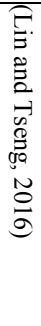 & 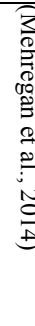 & & & 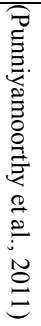 & 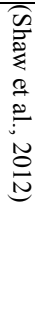 & 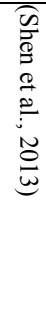 & & 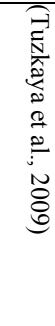 & 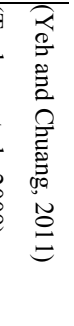 \\
\hline
\end{tabular}

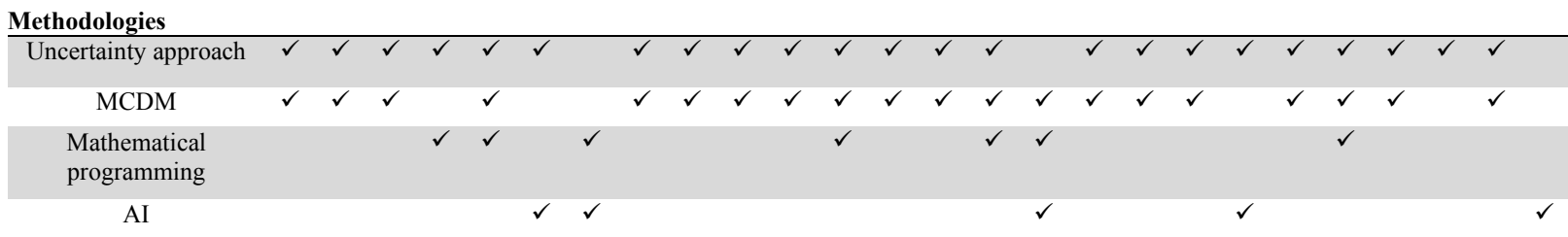

\subsubsection{MCDM}

In sustainable supplier selection, potential suppliers are evaluated according to the above three sets of criteria. The MCDM methods are the most common tool in the papers reviewed. The MCDM methods applied on the uncertain supplier selection problem are the fuzzy ranking method (Amindoust et al., 
2012), FTOPSIS (Awasthi et al., 2010; Lin \& Tseng; 2016; Shen et al., 2013), FAHP (Azadnia et al., 2015; Lee et al., 2009; Punniyamoorthy et al., 2011), Fuzzy ANP (FANP) (Büyüközkan \& Çifçi, 2012), Grey relational analysis (GRA)-ANP model of (Dou et al., 2014; Hashemi et al., 2015), AHP-GRA (Badri Ahmadi et al., 2017), fuzzy multi-attribute utility (Erol et al., 2011), FTOPSIS (Govindan et al., 2013), fuzzy axiomatic design of (Kannan et al., 2015), FDEMATEL (Mehregan et al., 2014), and the combined methods of FAHP and FTOPSIS (Kannan et al., 2013), and FANP and FPROMETHEE (Tuzkaya et al., 2009). Amindoust et al. (2012) developed a ranking method based on the Fuzzy Inference System (FIS) to evaluate the importance of the decision criteria and supplier performance according to those criteria. Awasthi et al. (2010) applied FTOPSIS to choose the alternatives with the highest environmental performance. They also analysed the sensitivity of the resultant criteria weights on the performance evaluation. Lin and Tseng (2016) adopted an interval-valued FTOPSIS to rank the competitive priorities of SSCM in electronics manufacturing focal firms in Taiwan. Shen et al. (2013) applied FTOPSIS for green supplier selection using environmental factors. The effectiveness of their approach was demonstrated by a numerical example. Azadnia et al. (2015) analysed the sustainability of suppliers by FAHP and a rule-based weighted fuzzy method in a case study of packaging films in the food industry. They considered four objectives of minimizing cost and maximizing social, environmental, and economic qualitative scores in the order allocation problem. Lee et al. (2009) applied the Delphi method to select the most important criteria for supplier selection and then used FAHP to evaluate green suppliers for a TFT-LCD manufacturer. Punniyamoorthy et al. (2011) combined structural equation modelling and FAHP to select suppliers, taking into account the safety and environmental concerns and costs. Büyüközkan and Çifçi (2012) developed an FANP method for sustainable supplier evaluation under incomplete preference relations which maintains the consistency among evaluations. To demonstrate the validity of the proposed model, a case in the white goods industry was studied. Dou et al. (2014) used a multi-stage grey-ANP model for evaluating green supplier development programs to improve supplier performance. Hashemi et al. (2015) considered economic and environmental criteria in the process of selecting green suppliers, and used ANP and an improved grey relational analysis to weight the criteria and rank the suppliers. Erol et al. (2011) used fuzzy entropy to find the weights of the indicators and fuzzy multi-attribute utility (FMAUT) to measure sustainable supply chain performance. Govindan et al. (2013) developed a model based on the TBL framework for supplier selection in the textile industry and then used FTOPSIS for performance evaluation and ranking. D. Kannan et al. (2015) proposed a fuzzy axiomatic design which evaluates the design and functional requirements to select the best green supplier for a plastics manufacturer. Mehregan et al. (2014) studied the interrelationships among the sustainability supplier selection criteria. They used ISM to extract these interrelationships and FDEMATEL to determine the intensity of these relationships in a case study in the gas industry. D. Kannan et al. (2013) applied FAHP and FTOPSIS to green supplier selection and then used an integrated approach of FMAUT and multi-objective programming (MOP) for order allocation on a vehicle maker. Tuzkaya et al. (2009) applied FANP and the Fuzzy PROMETHEE approach to evaluate supplier environmental performance. One of the most recent study, Fallahpour, Udoncy Olugu, Nurmaya Musa, Yew Wong, and Noori (2017), employed FPP and FTOPSIS to study a sustainable supplier selection problem.

\subsubsection{Mathematical programming}

The fuzzy enhanced DEA model of Azadi et al. (2015), integrated approach of rule-based weighted fuzzy method, FAHP, and MOP for a multi-period multi-product lot-sizing problem in Azadnia et al. (2015), integrated AHP and fuzzy multi-objective integer linear programming (MOILP) of Gupta et al. (2016), integrated approach of FMAUT and MOP (Kannan et al., 2013), and the combined FAHP and fuzzy multi-objective linear programming (FMOLP) (Shaw et al., 2012) are some application examples of mathematical programming for sustainable supplier selection. Azadi et al. (2015) developed an integrated DEA enhanced Russell measure (ERM) model in a fuzzy context to select the best sustainable supplier for a resin producer. Azadnia et al. (2015) analysed the sustainability of suppliers by FAHP and a rule-based weighted fuzzy method in a case study of packaging films in food industry. 
They considered four objectives of minimizing cost and maximizing social, environmental and economic scores in the order allocation problem. Gupta et al. (2016) integrated AHP and MOILP for sustainable vendor selection and order allocation problem through a weighted possibility programming approach. Shaw et al. (2012) addressed carbon emissions in supplier selection. They used FAHP to weight the factors and the extracted weights are then used in an MOLP for supplier selection and quota allocation.

\subsubsection{Artificial intelligence}

Applying artificial intelligence for sustainable supplier selection is scant. The data mining technique of grey based rough set theory in Bai and Sarkis (2010), genetic algorithms of Yeh and Chuang (2011), neighbourhood rough set theory of Bai and Sarkis (2014), integrated artificial neural network (ANN) of Kuo et al. (2010), and expert fuzzy rule-based system of Olugu and Wong (2012) are some examples of work which used AI for sustainable supplier selection. Bai and Sarkis (2010) used grey system theory to select the preferred sustainable suppliers. Rough set theory was used to handle the vagueness and ambiguity of the imprecise attributes. Yeh and Chuang (2011) considered four objectives of cost, time, product quality and green appraisal score for green partner selection. They used multi-objective genetic algorithms to find the Pareto-optimal solutions. Bai and Sarkis (2014) introduced a method to identify the sustainable supply chain key performance indicators (KPIs) that can then be used to evaluate the sustainability performance of suppliers. They utilized the neighbourhood rough set to determine the KPIs and data envelopment analysis (DEA) to evaluate the relative performance of the suppliers using the extracted KPIs. Kuo et al. (2010) developed a green supplier selection model by integrating artificial neural network (ANN) and DEA and ANP for a camera manufacturer. They conclude that their hybrid method outperforms the two hybrid methods of ANN-DEA and ANP-DEA. Olugu and Wong (2012) developed an expert fuzzy rule-based system for performance evaluation of a closed-loop green supply chain in the case of the automotive industry.

\subsection{Drawbacks of reviewed studies and the contributions of this paper}

From the literature review, three drawbacks were recognized. First, as sustainability is a threefold concept, it requires developing a holistic framework. Therefore, ignoring the economic performance of the suppliers in Awasthi et al. (2010), Shen et al. (2013), and Tuzkaya et al. (2009) or social criteria in Dou et al. (2014), Hashemi et al. (2015), Kannan et al. (2013), Shaw et al. (2012), and Tseng and Chiu (2013) are regarded as a failure in adopting a wholesome approach to sustainability. Second, according to Azadnia et al. (2015), most studies in green and sustainable supplier selection have introduced hypothetical examples rather than providing a real-world application. This study is among the very rare real-world application of the sustainable supplier selection. Third, as Hashemi et al. (2015) stated, the internal relationships among the evaluation criteria in SCM are generally neglected by decision makers because of the complexity of quantifying and the lack of explicit knowledge about these interactions.

Table 5

Summary of previous methods applied in sustainable supplier selection

\begin{tabular}{|c|c|c|c|c|c|c|c|c|c|c|c|c|c|c|c|c|c|c|c|c|c|c|c|c|c|}
\hline Methodologies & 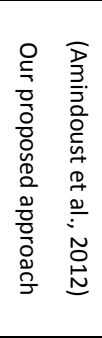 & 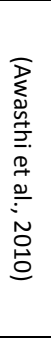 & 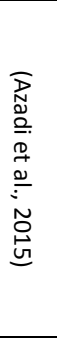 & 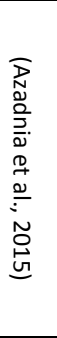 & 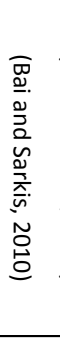 & 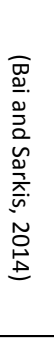 & 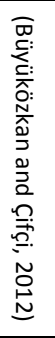 & 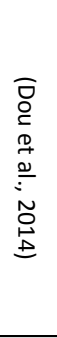 & 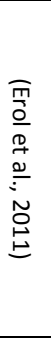 & 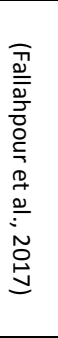 & 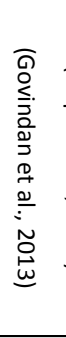 & 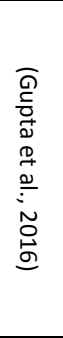 & 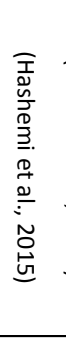 & 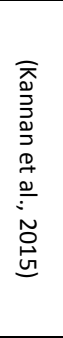 & 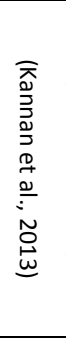 & 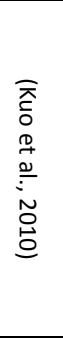 & 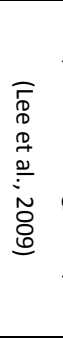 & 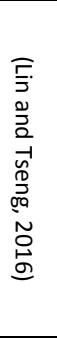 & 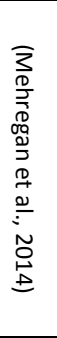 & 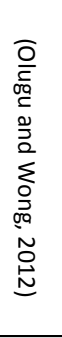 & 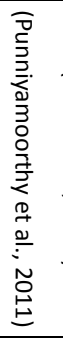 & 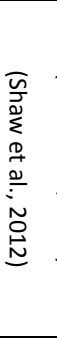 & 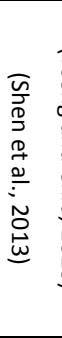 & 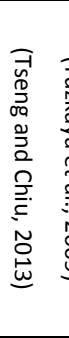 & 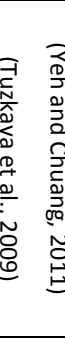 \\
\hline ISM & $\checkmark$ & & & & & & & & & & & & $\checkmark$ & & & & & & $\checkmark$ & & & & & & \\
\hline TOPSIS & $\checkmark$ & $\checkmark$ & & & & & $\checkmark$ & & & $\checkmark$ & $\checkmark$ & & $\checkmark$ & & $\checkmark$ & & & $\checkmark$ & & & & & $\checkmark$ & & \\
\hline ANP & $\checkmark$ & & & & & & $\checkmark$ & $\checkmark$ & & & & & $\checkmark$ & & & $\checkmark$ & & & & & & & & & $\checkmark$ \\
\hline FPP & $\checkmark$ & & & & & & & & & $\checkmark$ & & & & & & & & & & & & & & & \\
\hline DEMATEL & $\checkmark$ & & & & & & $\checkmark$ & & & & & & & & & & & & $\checkmark$ & & & & & & \\
\hline
\end{tabular}


To the best of our knowledge, this is the first attempt to weight sustainability criteria (based on TBL approach) in supplier selection with considering the interrelationships among them. Fourth, combining ISM, FDEMATEL, and FPP provide a much more efficient method in comparison with the traditional ANP for weighting the criteria by considering interrelationships between them. Last but not least, this is the only study which combines a group of well-employed methods like FDEMATEL, FPP, Supermatrix, and FTOPSIS in a logical sequence. A summary of previous studies employing individual methods is shown in Table 5. As it is clear in Table 5, in the literature there are some works on these methods, but there is not any research that combines these methods together. Thereby, this study proposes a new integrated approach that could cope with the interdependencies among various sustainability criteria in fuzzy environment. Further, the supplied case study provides additional insights for research and practical applications.

\section{Research Method}

According to the classification proposed by Wacker (1998), the present study is an analytical mathematical research. The steps followed in this study are as follow. First, a review of the sustainable supplier selection literature was performed and 31 criteria were identified. Second, semi-structured questionnaires and interviews with experts were used to select the most important criteria. We interviewed seven managers including procurement manager, project planning manager, procurement expert, project planning expert, foreign purchasing manager, project controlling supervisor, and chief executive officer (CEO). They were asked to participate in the project based on their familiarity with supplier evaluation issue, their relevant experience, and their willingness. It is worth mentioning that they all have at least 10-year experience in the field. The case project was a construction project in energy industry in Iran. For confidentiality reasons, the name of the project is not mentioned here. Third, the interrelationships among the selected criteria were determined by another questionnaire which constitutes a paired comparison matrix in the ISM method of Warfield (1974). Fourth, the FDEMATEL method of Lin and $\mathrm{Wu}$ (2008) was used to evaluation the intensity of the interrelations based on the expert opinions stated in the form of linguistic terms which were then converted to triangular fuzzy numbers (TFN) on a 9-point scale. Fifth, to obtain the relative weights of the selected criteria, we use the FANP method proposed by Rezaei, Ortt, and Scholten (2013) that combines FDEMATEL and FPP. Finally, FTOPSIS is used to rate the suppliers according to the qualitative and quantitative criteria. Figure 1 shows the steps of this research. Each method is fully explained below.

\subsection{Interpretive Structural Modelling (ISM)}

ISM is a learning process which maps the complex interactions among variables in a comprehensive and systematic model (Warfield, 1974). This methodology helps to identify and analyse the interrelationships among different elements of a system (Nishat Faisal et al., 2006). It also provides a visual representation of the importance and interactions among these elements. A Structural SelfInteraction Matrix (SSIM) is first developed to show the paired relationships among the criteria. Four symbols are used to indicate the relationships between criteria $i$ and $j$ ( 1 if $i$ only affects $j, 2$ if $i$ affects $j$ and $j$ affects $i,-1$ if $j$ only affects $i$, and 0 if no relation exists). SSIM is then converted into a zero-one Reachability Matrix (RM) to check on the transitivity. In the initial reachability matrix $D, \mathrm{C}_{i}$ represents criteria $i$. If $j$ is reachable from $i$, then $d_{i j}=1$, else $d_{i j}=0$. To avoid group effects, each expert was interviewed separately and the mode of opinions on each relationship was used in the integrated relationship (adjacent) matrix (Warfield, 1974).

$$
\begin{gathered}
C_{1} \\
C_{2} \\
D=C_{1} \\
C_{2} \\
\vdots \\
C_{n}
\end{gathered}\left[\begin{array}{cccc}
0 & d_{12} & \cdots & d_{1 n} \\
d_{21} & 0 & \cdots & d_{2 n} \\
\vdots & \vdots & \ddots & \vdots \\
d_{m 1} & d_{m 2} & \cdots & 0
\end{array}\right]
$$


The final Reachability Matrix is constructed based on the transitivity relations. For this purpose, the initial matrix $D$ is added to the identity matrix $I$ and raised to consecutive powers until a steady state $\mathrm{M}^{*}$ is established, where $M^{*}=M^{k}=M^{k+1}, k>1$.

ISM has its drawbacks. It does not provide any weights for the criteria (Kannan et al., 2009). We used FDEMATEL to measure the strength of the relations and FANP to determine the relative weights based on the relationships between the criteria. However, only the initial reachability matrix has been employed and the remaining steps have been ignored due to the use of ISM in this paper. For more details on ISM application in analysing interrelationships among sustainability criteria see Mehregan et al. (2014).

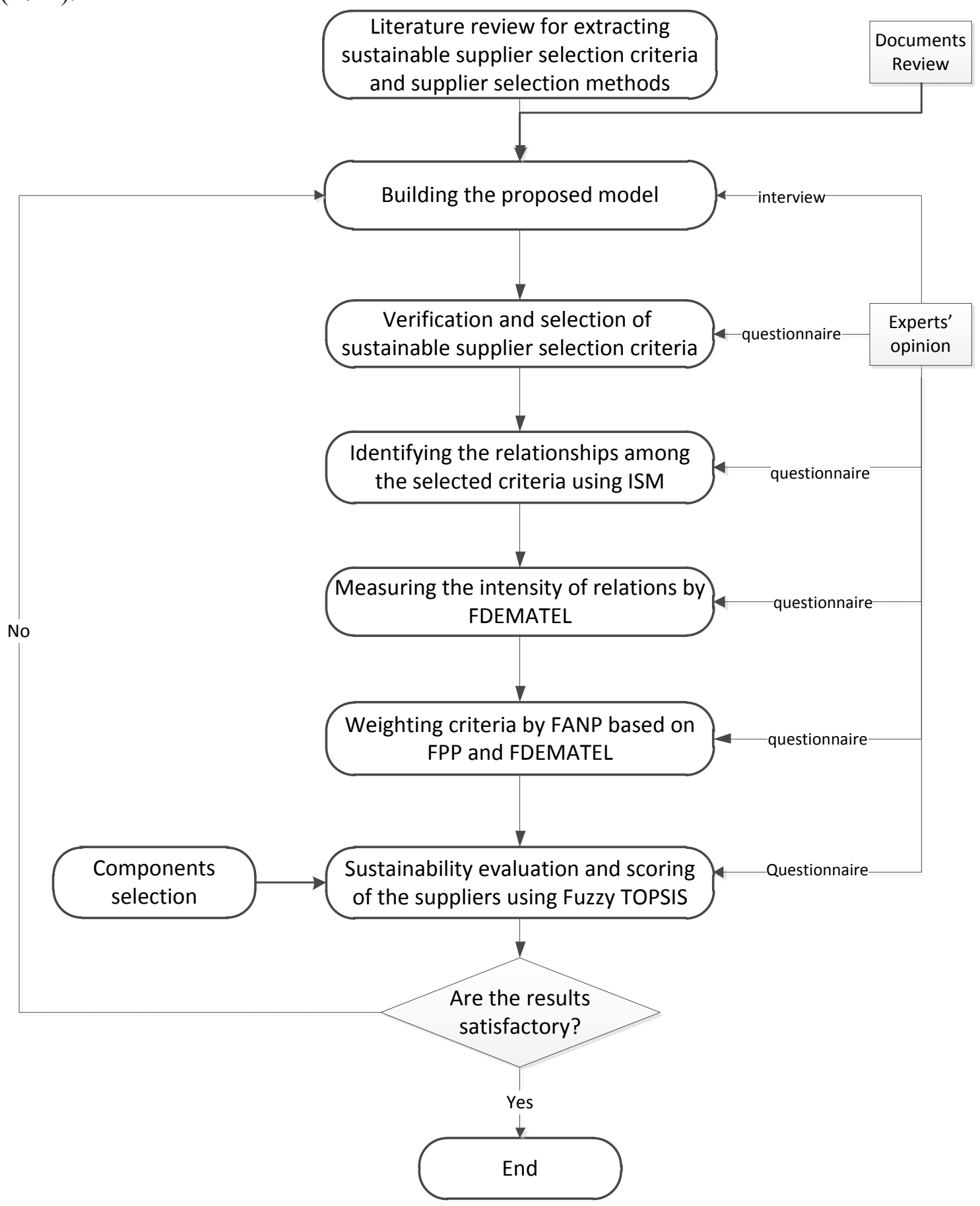

Fig. 1. Research steps 


\subsection{Fuzzy set theory}

Fuzzy set theory was first introduced by Zadeh (1965) to deal with subjective and vague human judgments. A fuzzy set $\tilde{a}$ is a class of objects (X) with grades of membership ( $\mu$ ). The grade of membership of $\mathrm{x}$ in $\tilde{a}$ or $\mu_{\tilde{a}}(x)$ maps each element $\mathrm{x} \in \mathrm{X}$ to a real number in $[0,1]$, which represents the degree in which $\mathrm{x}$ belongs to the fuzzy set. As $\mu_{\tilde{a}}(x)$ approaches 1 , the grade of membership of $\mathrm{x}$ in $\tilde{a}$ increases. $\mu_{\tilde{a}}(x)=1$ means absolute membership of $\mathrm{x}$ in the set and $\mu_{\tilde{a}}(x)=0$ means the element is not in that set. We used TFN here. TFN $\tilde{a}$ is represented by a tuple $(l, m, u)$, denoting the smallest, most promising and largest possible values of $\tilde{a}$ and $l<m<u$ (see Fig. 2). The membership function $\mu_{\tilde{a}}(x)$ of TFN $\tilde{a}$ is given by:

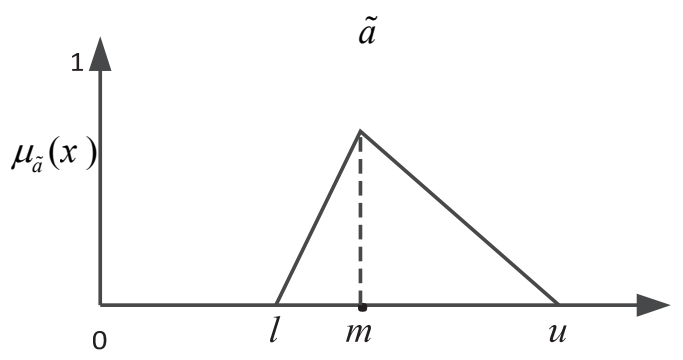

Fig. 2. Membership function of TFN $\tilde{a}$

$$
\mu_{\tilde{a}}(x)=\left\{\begin{array}{cl}
\frac{x-l}{m-l}, & l \leq x \leq m, \\
\frac{u-x}{u-m}, & m \leq x \leq u, \\
0, & \text { otherwise. }
\end{array}\right.
$$

For two TFNs $\tilde{a}_{1}=\left(l_{1}, m_{1}, u_{1}\right)$ and $\tilde{a}_{2}=\left(l_{2}, m_{2}, u_{2}\right)$, the main fuzzy operations (addition $\oplus$, subtraction $\ominus$, multiplication $\otimes$, and division $\oslash)$ are calculated as follows:

$\tilde{a}_{1} \oplus \tilde{a}_{2}=\left(l_{1}, m_{1}, u_{1}\right) \oplus\left(l_{2}, m_{2}, u_{2}\right)=\left(l_{1}+l_{2}, m_{1}+m_{2}, u_{1}+u_{2}\right)$

$\tilde{a}_{1} \ominus \tilde{a}_{2}=\left(l_{1}, m_{1}, u_{1}\right) \ominus\left(l_{2}, m_{2}, u_{2}\right)=\left(l_{1}-u_{2}, m_{1}-m_{2}, u_{1}-l_{2}\right)$

$\tilde{a}_{1} \otimes \tilde{a}_{2}=\left(l_{1}, m_{1}, u_{1}\right) \otimes\left(l_{2}, m_{2}, u_{2}\right)=\left(l_{1} \times l_{2}, m_{1} \times m_{2}, u_{1} \times u_{2}\right)$

$\tilde{a}_{1} \oslash \tilde{a}_{2}=\left(l_{1}, m_{1}, u_{1}\right) \oslash\left(l_{2}, m_{2}, u_{2}\right)=\left(l_{1} / u_{2}, m_{1} / m_{2}, u_{1} / l_{2}\right)$

and the distance between $\tilde{a}_{1}$ and $\tilde{a}_{2}$ is:

$$
d\left(\tilde{a}_{1}, \tilde{a}_{2}\right)=\sqrt{\frac{1}{3}\left[\left(l_{1}-l_{2}\right)^{2}+\left(m_{1}-m_{2}\right)^{2}+\left(u_{1}-u_{2}\right)^{2}\right]}
$$

\subsection{FDEMATEL}

DEMATEL constructs and analyses a structural model of causal relationships among the elements of a complex system (Lin \& Lin, 2008). The influencing factors are classified into two groups of causes and effects (Tsai et al., 2009). DEMATEL relies on expert opinions and comments, which are often unclear and descriptive. Therefore, we convert these judgments to fuzzy numbers (see Table 6). 
Table 6

Linguistic terms and corresponding numerical values of TFNs

\begin{tabular}{cc}
\hline Linguistic term & Numerical value \\
\hline Very High $(\mathrm{VH})$ & $(0.75,1,1)$ \\
High $(\mathrm{H})$ & $(0.5,0.75,1)$ \\
Low $(\mathrm{L})$ & $(0.25,0.5,0.75)$ \\
Very Low $(\mathrm{VL})$ & $(0,0.25,0.5)$ \\
None $(\mathrm{N})$ & $(0,0,0.25)$ \\
\hline
\end{tabular}

We follow Lin and $\mathrm{Wu}$ (2008) in using DEMATEL in a fuzzy setting. A total of $P$ experts are questioned to determine the relationships in the criteria set $C=\left\{c_{i} \mid i=1,2, \ldots, n\right\}$, which results in $P$ fuzzy matrices $\tilde{Z}^{(1)}, \tilde{Z}^{(2)}, \ldots, \tilde{Z}^{(P)}$ of the form:

$$
\tilde{Z}^{(k)}=\left[\begin{array}{cccc}
0 & \tilde{z}_{12}{ }^{(k)} & \cdots & \tilde{z}_{1 n}{ }^{(k)} \\
\tilde{z}_{21}{ }^{(k)} & 0 & \ldots & \tilde{z}_{2 n}{ }^{(k)} \\
\vdots & \vdots & \ddots & \vdots \\
\tilde{z}_{n 1}{ }^{(k)} & \tilde{z}_{n 2}{ }^{(k)} & \cdots & 0
\end{array}\right], \quad \mathrm{k}=1,2, \ldots, \mathrm{P}
$$

The average of the expert opinions is calculated to generate the initial direct-relation fuzzy matrix of aggregated opinions:

$$
\tilde{Z}=\frac{\left(\tilde{Z}^{(1)} \oplus \tilde{Z}^{(2)} \oplus \ldots \oplus \tilde{Z}^{(k)}\right)}{P},
$$

where $\tilde{\mathrm{z}}_{\mathrm{ij}}=\left(\mathrm{l}_{\mathrm{ij}}, \mathrm{m}_{\mathrm{ij}}, \mathrm{u}_{\mathrm{ij}}\right)$ is a TFN, $\tilde{\mathrm{z}}_{\mathrm{ii}}=(0,0,0)$, and $\oplus$ is fuzzy number addition. The normalized direct-relation fuzzy matrix $\tilde{X}$ is then obtained by normalizing $\tilde{Z}$ :

$$
\tilde{X}=\left[\begin{array}{cccc}
0 & \tilde{x}_{12} & \cdots & \tilde{x}_{1 n} \\
\tilde{x}_{21} & 0 & \cdots & \tilde{x}_{2 n} \\
\vdots & \vdots & \ddots & \vdots \\
\tilde{x}_{n 1} & \tilde{x}_{n 2} & \cdots & 0
\end{array}\right], \tilde{x}_{i j}=\frac{\tilde{z}_{i j}}{r}=\left(\frac{l_{i j}}{r}, \frac{m_{i j}}{r}, \frac{u_{i j}}{r}\right)
$$

where $r=\max _{1 \leq i \leq n}\left(\sum_{j=1}^{n} u_{i j}\right)$. Finally, the total fuzzy relation matrix $\tilde{T}$ is calculated:

$$
\begin{aligned}
\tilde{T} & =\lim _{k \rightarrow \infty}\left(\tilde{X}^{1}+\tilde{X}^{2}+\ldots+\tilde{X}^{k}\right) \\
\tilde{T} & =\left[\begin{array}{cccc}
0 & \tilde{t}_{12} & \cdots & \tilde{t}_{1 n} \\
\tilde{t_{21}} & 0 & \cdots & \tilde{t}_{2 n} \\
\vdots & \vdots & \ddots & \vdots \\
\tilde{t}_{n 1} & \tilde{t}_{n 2} & \cdots & 0
\end{array}\right]
\end{aligned}
$$

where $\tilde{t_{i j}}=\left(l_{i j}^{\prime \prime}, m_{i j}^{\prime \prime}, u_{i j}^{\prime \prime}\right)$ and $\left[l_{i j}^{\prime \prime}\right]=X_{l} \cdot\left(I-X_{l}\right)^{-1},\left[m_{i j}^{\prime \prime}\right]=X_{m} \cdot\left(I-X_{m}\right)^{-1},\left[u_{i j}^{\prime \prime}\right]=X_{u} \cdot\left(I-X_{u}\right)^{-1} \cdot \tilde{D}_{i}$ and $\tilde{R}_{i}$ are the sum of rows and sum of columns of $T$ respectively. $\left(\tilde{D}_{i}+\tilde{R}_{i}\right)^{\text {def }}$ indicates how interactive is a criterion, relative to the other criteria, hence how important is the criterion. $\left(\tilde{D}_{i}-\tilde{R}_{i}\right)^{\text {def }}$ measures the influence of a criterion; if it is positive, then the criterion is causal, and if it is negative, the criterion is dependent. The centre of gravity method is used for the defuzzification:

$$
t_{i j}=\frac{\left(u_{i j}^{\prime \prime}-l_{i j}^{\prime \prime}\right)+\left(m_{i j}^{\prime \prime}-l_{i j}^{\prime \prime}\right)}{3}+l_{i j}^{\prime \prime}
$$




\subsubsection{ANP}

ANP is the general form of AHP. AHP was developed by Saaty (1990) as an MCDM technique to solve complex decision-making problems. The premise of AHP is the assumption of the independence of higher levels from lower levels, and the independence of each criterion from the other criteria and factors at the same level. ANP was developed by Saaty and Takizawa (1986) to consider the dependency and interactions among the alternatives and criteria. ANP uses a measurement scale from 1 to 9 based on pairwise comparisons. The impact of all the elements on each other and their relative importance are considered in a large matrix called the supermatrix:

$$
\text { Criteria }\left[\begin{array}{ccc}
\text { Goal } \\
\text { Subcriteria }
\end{array}\left[\begin{array}{ccc}
0 & 0 & 0 \\
W_{21} & W_{22} & 0 \\
0 & W_{32} & W_{33}
\end{array}\right]\right.
$$

Vector $W_{21}$ shows the relative weights of criteria according to the goal, $w_{32}$ indicates the relative weights of sub-criteria according to the criteria, and $W_{22}$ and $W_{33}$ shows the interdependency among the criteria and sub-criteria respectively. Note that $W_{21}$ and $W_{32}$ is gained by FPP and $W_{22}$ and $W_{33}$ are obtained from the defuzzified total relationships matrix of FDEMATEL. According to Saaty and Takizawa (1986), ANP follows a four-step procedure. At first, the problem is presented as a network consisting of goal, criteria, and decision options. The logical relationships among them are formulated. Then, the elements of each cluster are compared against each other. The decision maker is asked to perform a series of pairwise comparisons so as to measure the dependencies and the impact of the sub-criteria. In the third step, the relative local priorities are entered in the columns of an unweighted supermatrix in order to achieve final priorities. To build a stochastic supermatrix, each column of the unweighted supermatrix is normalized so that sum of the values in each column is 1 . Finally, a weighted supermatrix is raised to consecutive powers until convergence happens and all entries in the columns are equal. The relative weight of each element is in the limiting supermatrix. It is possible to consider the alternatives in the supermatrix as well, but this increases the computational complexity of the problem. Therefore, we used the fuzzy extension of ANP for weighting purposes only. There are various FANP methods. In this paper, the combination of FDEMATEL and FAHP was used to form the FANP supermatrix. Among the approaches for FAHP, we applied the FPP method of Rezaei et al. (2013) for paired fuzzy comparisons as follows.

\subsubsection{Improved FPP}

FAHP was developed by Van Laarhoven and Pedrycz (1983) to incorporate the imprecise and ambiguous nature of judgments. One criticism of FAHP is that it often fails to consider the inconsistency of the opinions (Leung \& Cao, 2000). The FPP method proposed by Mikhailov (2003) preserves the preference intensities and provides a consistency index. We based our method on Rezaei et al. (2013) which extends the FPP method of Mikhailov (2003) to handle the non-linearity of the reciprocal fuzzy numbers as described below:

Step 1. Establish a hierarchy that includes the goal and criteria.

Step 2. Determine the pairwise comparison matrices to compare the criteria using the opinions from $k$ experts and convert them to numerical values (according to Table 5): 


$$
\begin{aligned}
& \begin{array}{llll}
\mathrm{C}_{1} & \mathrm{C}_{2} & \cdots & \mathrm{C}_{n}
\end{array} \\
& \tilde{A}_{k}=\begin{array}{c}
\mathrm{C}_{1} \\
\mathrm{C}_{2} \\
\vdots \\
\mathrm{C}_{n}
\end{array}\left[\begin{array}{cccc}
1 & \tilde{a}_{12 \mathrm{k}} & \cdots & \tilde{a}_{1 \mathrm{nk}} \\
1 / \tilde{a}_{12 \mathrm{k}} & 1 & \cdots & \tilde{a}_{2 \mathrm{nk}} \\
\vdots & \vdots & \ddots & \vdots \\
1 / \tilde{a}_{1 n \mathrm{k}} & 1 / \tilde{a}_{2 n \mathrm{k}} & \cdots & 1
\end{array}\right]
\end{aligned}
$$

where $\tilde{a}_{i j k}=\left(l_{i j k}, m_{i j k}, u_{i j k}\right)$ is a TFN which shows decision maker $k$ 's preference of criterion $i$ over $j$. It suffices that each decision maker (DM) provides at most $n(n-1) / 2$ pairwise comparisons $\tilde{a}_{i j} ; i, j \in(1,2, \ldots, n), j>i$, since $\tilde{a}_{j i}=1 / \tilde{a}_{i j}$. A pairwise comparison matrix of each part of the questionnaire from each expert is examined for consistency by calculating the CI and CR. If an inconsistency is present, the expert is asked to revise that part of the questionnaire. The fuzzy pairwise comparison matrices from all experts are combined by a geometric mean which constructs the fuzzy aggregated pairwise comparison matrices. With $k$ experts, a total of $k$ sets of pairwise comparison matrices represent the relationship among criteria. For each pairwise comparison between two elements, there are $k$ TFN's. Synthetic TFNs are obtained by the geometric mean $\tilde{a}_{i j}=\left(\tilde{a}_{i j 1} \otimes \tilde{a}_{i j 2} \otimes \cdots \otimes \tilde{a}_{i j k}\right)^{1 / k}(\otimes$ is fuzzy number multiplication $)$, which constitutes the fuzzy aggregated pairwise comparison matrix $\tilde{A}$.

Step 3. Derive the relative crisp importance weights (local priority) from each matrix using the FPP method.

There are two types of fuzzy numbers to compare the criteria: (i) TFNs $\tilde{1}, \tilde{2}, \tilde{3}, \ldots$ (known as Type I), with the membership function:

$$
\mu_{N}(x)=\left\{\begin{array}{cc}
\frac{x-l}{m-l}, & l \leq x \leq m, \\
\frac{u-x}{u-m}, & m \leq x \leq u, \\
0, & \text { otherwise. }
\end{array}\right.
$$

and (ii) the corresponding reciprocals of the TFNs Type I which are $\tilde{1}, \frac{\tilde{1}}{2}, \frac{\tilde{1}}{3}, \ldots$ (known as Type II), with the membership function:

$$
\mu_{\frac{1}{N}}(x)= \begin{cases}\frac{1}{(m-u) \cdot x}-\frac{u}{m-u}, & x \in\left[\frac{1}{u}, \frac{1}{m}\right], \\ \frac{1}{(m-l) x}-\frac{u}{m-l}, & x \in\left[\frac{1}{m}, \frac{1}{l}\right], \\ 0, & \text { otherwise. }\end{cases}
$$

The membership function of $x$ to $\tilde{a}_{i j}$ is monotone increasing in the interval $\left(l_{i j}, m_{i j}\right)$ and linearly decreasing in the interval $\left(m_{i j}, u_{i j}\right)$, while the reciprocal of a TFN is not linearly changing over its left and right intervals. A DM's satisfaction is measured by the following membership functions:

$$
\mu_{i j}\left(\frac{w_{i}}{w_{j}}\right)= \begin{cases}\frac{\frac{w_{i}}{w_{j}}-l_{i j}}{m_{i j}-l_{i j}}, & \frac{w_{i}}{w_{j}} \leq m_{i j}, \\ \frac{u_{i j}-\frac{w_{i}}{w_{j}}}{u_{i j}-m_{i j}}, & \frac{w_{i}}{w_{j}} \geq m_{i j} .\end{cases}
$$




$$
\mu_{j i}\left(\frac{w_{j}}{w_{i}}\right)= \begin{cases}\frac{\frac{w_{j}}{w_{i}}-l_{j i}}{m_{j i}-l_{j i}}, & \frac{w_{j}}{w_{i}} \leq m_{j i}, \\ \frac{u_{j i}-\frac{w_{j}}{w_{i}}}{u_{j i}-m_{j i}}, & \frac{w_{j}}{w_{i}} \geq m_{j i} .\end{cases}
$$

The membership function of the solution $P$ is $\lambda=\mu_{P}(w)=\min _{i j}\left\{\mu_{i j}(w)|i, j \in(1,2, \ldots, n), j\rangle i\right\}$. The optimal solution has the maximum degree of membership, so the problem is transformed to:

$\max \lambda$

subject to

$$
\begin{aligned}
& \left.\begin{array}{l}
\left(m_{i j}-l_{i j}\right) \lambda w_{j}-w_{i}+l_{i j} w_{j} \leq 0, \\
\left(u_{i j}-m_{i j}\right) \lambda w_{j}+w_{i}-u_{i j} w_{j} \leq 0,
\end{array}\right\} \text { for fuzzy number of type I } \\
& \left.\begin{array}{l}
\left(m_{j i}-l_{j i}\right) \lambda w_{i}-w_{j}+l_{j i} w_{i} \leq 0, \\
\left(u_{j i}-m_{j i}\right) \lambda w_{i}+w_{j}-u_{j i} w_{i} \leq 0,
\end{array}\right\} \text { for fuzzy number of type II } \\
& \sum_{k=1}^{n} w_{k}=1 \text {, } \\
& w_{k}>0 \text {, } \\
& i, j, k \in(1,2, \ldots, n), j>i \text {. }
\end{aligned}
$$

A positive value of $\lambda^{*}$ implies consistent pairwise comparisons, $\lambda^{*}=1$ indicates full consistency, and a negative value of $\lambda^{*}$ implies strong inconsistency.

\subsection{FTOPSIS}

TOPSIS, as developed by Yoon and Hwang (1981), is to provide a positive ideal solution and a negative ideal solution in order to find the best solution. The positive ideal solution (in contrast to the negative ideal solution) maximizes the profit criteria and minimizes the cost criteria. The best solution has the minimum distance from the positive ideal solution and the maximum distance from the negative ideal solution. We applied the method of Kaya and Kahraman (2011) for using TOPSIS in a fuzzy setting. $\tilde{Z}^{(k)}$ is the decision matrix of expert $k$ :

$$
\tilde{Z}^{(k)}=\left[\begin{array}{cccc}
\tilde{z}_{11}{ }^{(k)} & \tilde{z}_{12}{ }^{(k)} & \cdots & \tilde{z}_{1 n}{ }^{(k)} \\
\tilde{z}_{21}{ }^{(k)} & \tilde{z}_{22}{ }^{(k)} & \cdots & \tilde{z}_{2 n}{ }^{(k)} \\
\vdots & \vdots & \ddots & \vdots \\
\tilde{z}_{m 1}{ }^{(k)} & \tilde{z}_{m 2}{ }^{(k)} & \cdots & \tilde{z}_{m n}{ }^{(k)}
\end{array}\right], \mathrm{k}=1,2, \ldots, \mathrm{P}
$$

The average of expert opinions is calculated:

$$
\tilde{D}=\frac{\left(\tilde{Z}^{(1)} \oplus \tilde{Z}^{(2)} \oplus \ldots \oplus \tilde{Z}^{(k)}\right)}{P}
$$

Linear normalization is used to transform the various criteria scales into a comparable scale. The normalized fuzzy decision matrix $\tilde{R}=\left[\tilde{r}_{i j}\right]_{m \times n}$ is calculated by:

$$
\tilde{r}=\left(\frac{a_{i j}}{c_{j}^{*}}, \frac{b_{i j}}{c_{j}^{*}}, \frac{c_{i j}}{c_{j}^{*}}\right), j \in B ;
$$




$$
\begin{aligned}
& \tilde{r}=\left(\frac{a_{j}^{-}}{c_{i j}}, \frac{a_{j}^{-}}{b_{i j}}, \frac{a_{j}^{-}}{a_{i j}}\right), j \in C ; \\
& c_{j}^{*}=\max c_{i j}, j \in B, a_{j}^{-}=\min a_{i j}, j \in C
\end{aligned}
$$

where $B$ and $C$ are the sets of benefit and cost criteria, respectively. Multiplying the weights of the criteria in their respective columns results in a weighted normalized matrix $\tilde{V}=\left[\tilde{v_{i j}}\right]_{m \times n}$. $A^{*}=\left({\tilde{v_{1}}}_{1}^{*}, \tilde{v}_{2}^{*}, \ldots, \tilde{v}_{n}^{*}\right)$ and $A^{-}=\left(\tilde{v_{1}^{-}}, \tilde{v_{2}^{-}}, \ldots, \tilde{v}_{n}^{-}\right)$denote the fuzzy positive ideal solution (FPIS) and fuzzy negative ideal solution (FNIS) respectively. $\left(d_{i}^{+}\right)$is the distance of each alternative from FPIS and $\left(d_{i}^{-}\right)$ is the distance from FNIS respectively, found from:

$$
d\left(\tilde{v_{i}}, v^{*}\right)=\sqrt{\frac{1}{3}\left(\sum_{j=1}^{n}\left(\left(v_{i j}^{l}-v_{j}^{*, l}\right)+\left(v_{i j}^{m}-v_{j}^{*, m}\right)+\left(v_{i j}^{u}-v_{j}^{*, u}\right)\right)\right.}, i=1,2, \ldots, m
$$

Finally, the closeness coefficient of each alternative is computed to yield the ranking of the alternatives:

$$
C C_{i}=\frac{d_{i}^{-}}{d_{i}^{+}+d_{i}^{-}}
$$

As $C C_{i}$ approaches 1, the alternative gets closer to FPIS and farther from FNIS.

\section{Results}

\subsection{Criteria selection for evaluating the sustainability of suppliers}

We applied our methodology to rank the suppliers for a construction project in the energy sector. More than $70 \%$ of the budget for this project (estimated at billions of dollars) is allocated to the procurement of products which highlights the importance of the evaluation and selection of suppliers. 31 sub-criteria were identified during the review of the literature on sustainable supplier selection and interviews with the experts. The experts were asked to rate the importance of each criterion on a 5-point Likert scale in a questionnaire. Then, the most important criteria (based on the threshold of 4) were selected.

Fourteen criteria that most respondents considered to be of high (level 4 or 5) importance were chosen, namely, C1: Costs (including the costs of ordering, purchasing, and product launches), C2: Quality (acceptable failure rates), C3: Delivery (rate of on-time delivery, delivery efficiency, and delivery reliability), C4: Technology capability (ability to meet customer demand), C5: Relationships (close relationship, long-term relationship, relationship openness, history of collaboration with suppliers, and supplier reputation), C6: Services (after sales customer services such as guarantee and warranty, spare parts replacement guarantee, and providing tutorials on the use of the products purchased), C7: Environmental management system (environment certificates such as ISO 14000 and continuous measurement of environmental performance), C8: Resource and energy consumption (initiatives for reducing energy consumption or increasing energy efficiency, energy management standards such as ISO 50001), C9: Work safety and labour health (implementation of HSE management system and commitment to the health and safety of human resource), C10: Information disclosure (providing nonfinancial information to all stakeholders, publishing economic, environmental, and social performance reports, and availability of all required information about the firm), C11: stakeholder rights (satisfaction of all stakeholders, including the firm, suppliers, customers, distributors, society, NGOs, and government), C12: Staff competencies (skills, education, and relevant work experiences of human resources), C13: Local communities and social responsibility (supporting local development), and C14: Compliance with policies and regulations (respect for government regulations and tracking the compliance with these regulations in company documentations). 


\subsection{Identification of the relationships among sustainability criteria}

Respondents were asked to compare each pair of criteria and choose from one of three modes of relationships (one-sided, two-way, or no relationship). To avoid group effects, each expert was interviewed separately. The majority (mode) of votes, according to Warfield (1974), determined the state of the relationships in SSIM. Below is the result of this research step.

Table 7

Initial reachability matrix

\begin{tabular}{|c|c|c|c|c|c|c|c|c|c|c|c|c|c|c|}
\hline & C1 & $\mathrm{C2}$ & C3 & C4 & C5 & C6 & C7 & C8 & C9 & C10 & C11 & C12 & C13 & C14 \\
\hline $\mathrm{C} 1$ & 0 & 1 & 0 & 0 & 1 & 1 & 0 & 0 & 0 & 0 & 1 & 0 & 0 & 0 \\
\hline $\mathrm{C} 2$ & 1 & 0 & 0 & 0 & 1 & 1 & 1 & 0 & 0 & 1 & 1 & 0 & 0 & 1 \\
\hline C3 & 1 & 0 & 0 & 0 & 0 & 0 & 0 & 0 & 0 & 0 & 1 & 0 & 0 & 0 \\
\hline C4 & 1 & 1 & 1 & 0 & 1 & 1 & 1 & 1 & 1 & 1 & 1 & 1 & 0 & 1 \\
\hline C5 & 0 & 0 & 1 & 0 & 0 & 1 & 0 & 0 & 0 & 1 & 0 & 0 & 0 & 0 \\
\hline C6 & 1 & 0 & 0 & 0 & 1 & 0 & 0 & 0 & 0 & 0 & 1 & 0 & 0 & 0 \\
\hline C7 & 1 & 1 & 0 & 0 & 1 & 0 & 0 & 1 & 1 & 1 & 1 & 0 & 0 & 1 \\
\hline C8 & 1 & 1 & 0 & 1 & 0 & 0 & 1 & 0 & 0 & 1 & 1 & 0 & 0 & 1 \\
\hline C9 & 1 & 1 & 0 & 0 & 1 & 0 & 1 & 1 & 0 & 1 & 0 & 1 & 0 & 1 \\
\hline $\mathrm{C} 10$ & 0 & 0 & 0 & 0 & 1 & 0 & 0 & 0 & 0 & 0 & 1 & 0 & 0 & 0 \\
\hline C11 & 0 & 0 & 0 & 0 & 1 & 0 & 0 & 0 & 0 & 0 & 0 & 0 & 0 & 0 \\
\hline $\mathrm{C} 12$ & 1 & 1 & 1 & 1 & 1 & 1 & 1 & 1 & 1 & 0 & 0 & 0 & 1 & 1 \\
\hline C13 & 0 & 1 & 1 & 1 & 0 & 1 & 0 & 0 & 0 & 1 & 1 & 1 & 0 & 1 \\
\hline C14 & 0 & 1 & 0 & 1 & 0 & 1 & 1 & 1 & 1 & 1 & 0 & 0 & 0 & 0 \\
\hline
\end{tabular}

\subsection{Weighting the criteria}

\subsubsection{Internal relationships between criteria}

Having found the presence/absence of relations between the criteria, two matrices were distributed among the experts, which questioned the intensity of relations and the relative importance of the criteria in terms of linguistic variables. Using ISM contributes to the efficiency of our proposed methodology because only 85 paired comparisons for obtaining relative strength between criteria were asked from each expert (instead of 182 possible relations). So, reducing the computational demands of FDEMATEL is a major benefit of combining ISM and FDEMATEL. Following the Eqs. (9)-(13), the defuzzified matrix T has been obtained. For instance, table 8 shows the fuzzy and defuzzified aggregate matrix of internal relationships between the criteria. Then, the defuzzified aggregate relations matrix is used to determine the internal relationships between the sustainability criteria and sub-criteria in the final supermatrix. Thus, combining FDEMATEL and AHP provides an efficient method to obtain the relative weights with considering interrelationships.

Table 8

Fuzzy and defuzzified aggregate matrix of relationships among TBL dimensions

\begin{tabular}{lcccccccccccc}
\hline & \multicolumn{4}{c}{ Economic } & \multicolumn{4}{c}{ Environmental } & \multicolumn{4}{c}{ Social } \\
& $l$ & $m$ & $u$ & $d e f^{*}$ & $l$ & $m$ & $u$ & $d e f$ & $l$ & $m$ & $u$ & $d e f$ \\
\hline Economic & 0.167 & 0.167 & 0.167 & 0.232 & 0.058 & 0.1 & 0.133 & 0.164 & 0.058 & 0.1 & 0.142 & 0.169 \\
Environmental & 0.017 & 0.058 & 0.1 & 0.104 & 0.167 & 0.167 & 0.167 & 0.232 & 0.05 & 0.092 & 0.133 & 0.152 \\
$\quad$ Social & 0.042 & 0.075 & 0.117 & 0.129 & 0.042 & 0.083 & 0.125 & 0.142 & 0.167 & 0.167 & 0.167 & 0.236 \\
\hline *defuzzified & & & & & & & & & & & &
\end{tabular}




\subsubsection{Finding global weights}

The proposed approach is used to determine the global weights of the criteria. In order to have a stochastic or weighted supermatrix, the entries in each column are divided by the sum of their respective column's entries. The weighted supermatrix converges when raised to the power of 65 and turns into the limiting supermatrix where all entries in each row are equal to the weight of the criterion in FANP. Table 9 compares the results of FAHP and FANP (weights obtained by supermatrix). As it is shown, there is significant difference between these two rows. Based on FAHP, cost and quality are the most important criteria, whereas according to FANP staff competency and technology capability obtained the highest weights.

Table 9

Relative weights of sustainability criteria with and without using internal relations

\begin{tabular}{ccccccccccccccc}
\hline & C1 & C2 & C3 & C4 & C5 & C6 & C7 & C8 & C9 & C10 & C11 & C12 & C13 & C14 \\
\hline FAHP & 0.235 & 0.135 & 0.071 & 0.063 & 0.044 & 0.087 & 0.18 & 0.067 & 0.015 & 0.009 & 0.031 & 0.026 & 0.018 & 0.017 \\
FANP & 0.005 & 0.028 & 0 & 0.169 & 0 & 0.001 & 0.071 & 0.066 & 0.154 & 0 & 0 & 0.244 & 0.14 & 0.124 \\
\hline
\end{tabular}

\subsection{Supplier evaluation}

During the interviews, five strategic components for the construction project (i.e., electrical cable and instrument, actuated valve, telephone and paging, filter and scrubber, and air gas cooler) and 14 local and international suppliers were chosen for this study. The experts' opinions for scoring the sustainability of 14 suppliers using criteria were aggregated by an arithmetic mean according to Eq. (27). Finally, having obtained the positive and negative ideal vectors, the distance of each alternative from these ideals, the closeness coefficients and consequently the ranks of suppliers are determined. Table 10 compares the ranking of suppliers with (i.e., FANP) and without (i.e., FAHP) considering the internal relations. There is a significant difference between the results of the two approaches. These results were shown to the experts and according to them, considering interdependencies among criteria leads to a more reasonable output. Considering the internal relationships among criteria, supplier 5 obtained the best score, supplier 12 stood on second rank, and supplier 3 gained third rank.

Table 10

Suppliers ranked based on qualitative sustainability criteria with and without considering internal relations

\begin{tabular}{ccccccccc}
\hline $\begin{array}{c}\text { Weighting } \\
\text { Supplier }\end{array}$ & $\mathrm{d}^{+}$ & $\mathrm{d}^{-}$ & $\mathrm{FANP}$ & $\mathrm{Rank}$ & $\mathrm{d}^{+}$ & $\mathrm{d}^{-}$ & $\mathrm{CC}$ & Rank \\
\hline S1 & 0.153 & 0.161 & 0.512 & 12 & 0.146 & 0.226 & 0.608 & 10 \\
S2 & 0.137 & 0.144 & 0.511 & 13 & 0.106 & 0.201 & 0.655 & 7 \\
S3 & 0.094 & 0.179 & 0.655 & 3 & 0.099 & 0.217 & 0.688 & 5 \\
S4 & 0.104 & 0.196 & 0.653 & 4 & 0.133 & 0.177 & 0.571 & 11 \\
S5 & 0.090 & 0.190 & 0.678 & 1 & 0.092 & 0.229 & 0.715 & 2 \\
S6 & 0.173 & 0.137 & 0.443 & 16 & 0.225 & 0.138 & 0.381 & 16 \\
S7 & 0.129 & 0.153 & 0.544 & 11 & 0.119 & 0.210 & 0.639 & 9 \\
S8 & 0.156 & 0.141 & 0.474 & 15 & 0.162 & 0.180 & 0.526 & 14 \\
S9 & 0.095 & 0.177 & 0.651 & 5 & 0.128 & 0.240 & 0.651 & 8 \\
S10 & 0.127 & 0.163 & 0.562 & 10 & 0.126 & 0.242 & 0.657 & 6 \\
S11 & 0.165 & 0.165 & 0.500 & 14 & 0.184 & 0.136 & 0.425 & 15 \\
S12 & 0.096 & 0.183 & 0.656 & 2 & 0.079 & 0.236 & 0.750 & 1 \\
S13 & 0.114 & 0.150 & 0.567 & 9 & 0.150 & 0.182 & 0.548 & 12 \\
S14 & 0.129 & 0.177 & 0.578 & 8 & 0.098 & 0.243 & 0.712 & 3 \\
\hline
\end{tabular}




\section{Discussion}

A number of useful implications and interpretations could be derived from the proposed approach and its application in the real world case. Firstly, in terms of the capability of the proposed FANP, the experts confirmed that considering the interdependencies among criteria was a significant and valuable characteristic to them. In addition, they found the relationship matrix (first step of ISM) a very useful method to aggregate their opinions towards paying attention the interrelationships among different criteria, alternatives, and policies in practice. This result is in agreement with some studies like Dou et al. (2014). Second, the result of the two methods (FAHP and FANP) unearthed their hidden concerns regarding the importance of technology capability and staff competencies of the suppliers. Surprisingly, they found that suppliers 5 and 12 have not only gained the best score by FANP, but also by FAHP. According to the experts, they are efficient suppliers since they are completely utilizing their technologies and staff knowledge. Conversely, some suppliers, like supplier 4, have gained good score by FANP-FTOPSIS, but not by FAHP-FTOPSIS. Again, experts mentioned that in particular supplier 4 has just purchased high quality technologies but it doesn't have enough qualified technician to utilize them well. However, this was not the same for all other suppliers. One reason might be that, as interviewing team felt, experts were more interested to carefully evaluate and discuss the top suppliers and when it turns to discussing weaker suppliers a lack of enthusiasm was evident. Third, to help respondents around the difference between FAHP and FANP, we showed table 6 and 8 to them. In other words, we conducted a sensitivity analysis by comparing the results by FAHP, FANP and FTOPSIS based on two different scenarios: (1) considering internal relationships among the criteria, and (2) ignoring internal relationships among the criteria. According to table 8, staff competency and technology capability have gained the highest weights. This is justifiable by looking at table 6 . According to table 6, these two criteria have the most influencing power over other criteria. Influencing power of a criterion can be computed by counting ones in its row at table 6 . On the other hand, cost and quality have a high dependence power. Dependence power can be computed by counting ones in each criterion's column. Thus, it becomes clear why some criteria like cost and quality have high relative weight by FAHP, and at the same time low relative weight by FANP. Furthermore, these differences lead to significant different in suppliers' ranking at Table 9.

In order to simplify the evaluation process by using the proposed approach, following recommendation by Yang and Chen (2006), a program written in EXCEL has been developed to automatically calculate the mathematical analysis. According to the participants, the usage of this methodology has been very convenient for their future applications. Actually, without developing this simple program, it wasn't easy enough for the users to apply the proposed methodology. The research team interviewed and discussed with the evaluators, and they all agree that the integrated model is much feasible by using the decision-aiding program.

The proposed methodology used for solving the defined problem has, to our knowledge, no limitations and can be applied for solving any MADM problem. The problem could arise because of the complexity of the model in the case of considering a large number of factors, criteria and alternatives, but the real problems generally don't have these dimensions. Another problem could be the unfamiliarity of the users with the proposed methods, but the friendly EXCEL based program could help the participants overcoming this barrier.

\section{Conclusion}

SSCM is still a relatively new concept in Iran, but several companies have started to realize its importance due to the Iranian government's legislation on sustainable development. As a result, many companies have begun to demonstrate their commitment to implementing sustainability principles. In this study, we proposed an integrated approach to rank suppliers of in energy sector according to the sustainability criteria. Fourteen criteria were selected and approved using a semi-structured 
questionnaire to assess the sustainability of current suppliers. Relationship matrix was used to gain insights into the relationship between these criteria. Fuzzy DEMATEL was used to determine the intensity of the identified relationships, and FANP were used to weight the criteria. Sustainability performance of fourteen suppliers was evaluated by using FTOPSIS and weights obtained by FANP. We also showed that the final decision is very sensitive to the interrelationships among criteria. The integrated methodology used in this study offered a more precise and accurate analysis by considering interdependent relationships within and among a set of sustainability criteria.

Three main contributions of our work are: (i) combining ISM, FDEMATEL, FPP and supermatrix to weight the criteria considering the internal relations between the criteria, and (ii) a hybrid of ISM, FDEMATEL, FPP, and FTOPSIS to evaluate suppliers with and without considering the internal relations among criteria. We suggest the following directions for future study: (1) replicating the proposed methodology in the same and different application fields and studying the effectiveness of this approach, (2) Investigating the application of some other methods like cognitive mapping, to analyse the interrelationships among sustainability criteria, and (3) Since the procurement was carried out at the start of the project, we considered the supplier evaluation process to be a static problem. A dynamic extension of the proposed methodology, by considering ad hoc information, leads to a multistage and continuous model which provides more implications for academics and practitioners. Finally, according to the general acceptance of leanness and agility as the main supply chain strategies (El Mokadem \& El Mokadem, 2017), one study could differentiate the sustainability criteria according to their tendency towards leanness or agility.

Despite the important contributions of this study, it has some limitations. First limitation was the unavailability of official documents regarding real data of procurement due to confidentiality and also the lack of quantitative evaluation of environmental and social performance of suppliers. However, expert judgements and linguistic variables were used to overcome this limitation. Second, the results of this study may not be generalizable and future studies need to customize the relevant sustainability criteria, and perform independent study on internal relationships among selected criteria. However, this is also true for all the alternatives to our proposed approach in the literature, and, in general, is a limitation based by the MADM research.

\section{References}

Ahi, P., \& Searcy, C. (2013). A comparative literature analysis of definitions for green and sustainable supply chain management. Journal of Cleaner Production, 52, 329-341.

Amindoust, A., Ahmed, S., Saghafinia, A., \& Bahreininejad, A. (2012). Sustainable supplier selection: A ranking model based on fuzzy inference system. Applied Soft Computing, 12(6), 1668-1677.

Asadi, E., \& Sadjadi, S. (2017). Optimization methods applied to renewable and sustainable energy: A review. Uncertain Supply Chain Management, 5(1), 1-26.

Awasthi, A., Chauhan, S. S., \& Goyal, S. K. (2010). A fuzzy multicriteria approach for evaluating environmental performance of suppliers. International Journal of Production Economics, 126(2), 370-378.

Azadi, M., Jafarian, M., Saen, R. F., \& Mirhedayatian, S. M. (2015). A new fuzzy DEA model for evaluation of efficiency and effectiveness of suppliers in sustainable supply chain management context. Computers \& Operations Research, 54, 274-285.

Azadnia, A. H., Saman, M. Z. M., \& Wong, K. Y. (2015). Sustainable supplier selection and order lotsizing: an integrated multi-objective decision-making process. International Journal of Production Research, 53(2), 383-408.

Badri Ahmadi, H., Hashemi Petrudi, S. H., \& Wang, X. (2017). Integrating sustainability into supplier selection with analytical hierarchy process and improved grey relational analysis: a case of telecom industry. The International Journal of Advanced Manufacturing Technology, 90(9), 2413-2427. doi:10.1007/s00170-016-9518-z 
Bai, C., \& Sarkis, J. (2010). Integrating sustainability into supplier selection with grey system and rough set methodologies. International Journal of Production Economics, 124(1), 252-264.

Bai, C., \& Sarkis, J. (2014). Determining and applying sustainable supplier key performance indicators. Supply Chain Management: An International Journal, 19(3), 275-291.

Büyüközkan, G., \& Çifçi, G. (2012). A novel hybrid MCDM approach based on fuzzy DEMATEL, fuzzy ANP and fuzzy TOPSIS to evaluate green suppliers. Expert Systems with Applications, 39(3), 3000-3011.

Chai, J., Liu, J. N., \& Ngai, E. W. (2013). Application of decision-making techniques in supplier selection: A systematic review of literature. Expert Systems with Applications, 40(10), 3872-3885.

Chopra, S., \& Meindl, P. (2007). Supply chain management. Strategy, planning \& operation. Das summa summarum des management, 265-275.

Ciliberti, F., De Haan, J., De Groot, G., \& Pontrandolfo, P. (2011). CSR codes and the principal-agent problem in supply chains: four case studies. Journal of Cleaner Production, 19(8), 885-894.

Ciliberti, F., Pontrandolfo, P., \& Scozzi, B. (2008). Logistics social responsibility: Standard adoption and practices in Italian companies. International Journal of Production Economics, 113(1), 88-106.

Dao, V., Langella, I., \& Carbo, J. (2011). From green to sustainability: Information Technology and an integrated sustainability framework. The Journal of Strategic Information Systems, 20(1), 63-79.

Dou, Y., Zhu, Q., \& Sarkis, J. (2014). Evaluating green supplier development programs with a greyanalytical network process-based methodology. European Journal of Operational Research, 233(2), 420-431.

El Mokadem, M., \& El Mokadem, M. (2017). The classification of supplier selection criteria with respect to lean or agile manufacturing strategies. Journal of Manufacturing Technology Management, 28(2), 232-249.

Elkington, J. (1997). Cannibals with forks. The triple bottom line of 21 st century.

Erol, I., Sencer, S., \& Sari, R. (2011). A new fuzzy multi-criteria framework for measuring sustainability performance of a supply chain. Ecological Economics, 70(6), 1088-1100.

Fallahpour, A., Udoncy Olugu, E., Nurmaya Musa, S., Yew Wong, K., \& Noori, S. (2017). A decision support model for sustainable supplier selection in sustainable supply chain management. Computers \& Industrial Engineering, 105(Supplement C), 391-410.

Govindan, K., Khodaverdi, R., \& Jafarian, A. (2013). A fuzzy multi criteria approach for measuring sustainability performance of a supplier based on triple bottom line approach. Journal of Cleaner Production, 47, 345-354.

Gupta, P., Govindan, K., Mehlawat, M. K., \& Kumar, S. (2016). A weighted possibilistic programming approach for sustainable vendor selection and order allocation in fuzzy environment. The International Journal of Advanced Manufacturing Technology, 86(5-8), 1785-1804.

Hashemi, S. H., Karimi, A., \& Tavana, M. (2015). An integrated green supplier selection approach with analytic network process and improved Grey relational analysis. International Journal of Production Economics, 159, 178-191.

Hassini, E., Surti, C., \& Searcy, C. (2012). A literature review and a case study of sustainable supply chains with a focus on metrics. International Journal of Production Economics, 140(1), 69-82.

Joung, C. B., Carrell, J., Sarkar, P., \& Feng, S. C. (2013). Categorization of indicators for sustainable manufacturing. Ecological Indicators, 24, 148-157.

Kausar, K., Garg, D., \& Luthra, S. (2017). Key enablers to implement sustainable supply chain management practices: An Indian insight. Uncertain Supply Chain Management, 5(2), 89-104.

Kannan, D., Govindan, K., \& Rajendran, S. (2015). Fuzzy Axiomatic Design approach based green supplier selection: a case study from Singapore. Journal of Cleaner Production, 96, 194-208.

Kannan, D., Khodaverdi, R., Olfat, L., Jafarian, A., \& Diabat, A. (2013). Integrated fuzzy multi criteria decision making method and multi-objective programming approach for supplier selection and order allocation in a green supply chain. Journal of Cleaner Production, 47, 355-367.

Kannan, G., Pokharel, S., \& Kumar, P. S. (2009). A hybrid approach using ISM and fuzzy TOPSIS for the selection of reverse logistics provider. Resources, Conservation and Recycling, 54(1), 28-36. 
Kaya, T., \& Kahraman, C. (2011). Multicriteria decision making in energy planning using a modified fuzzy TOPSIS methodology. Expert Systems with Applications, 38(6), 6577-6585.

Kuo, R. J., Wang, Y. C., \& Tien, F. C. (2010). Integration of artificial neural network and MADA methods for green supplier selection. Journal of Cleaner Production, 18(12), 1161-1170.

Lee, A. H., Kang, H.-Y., Hsu, C.-F., \& Hung, H.-C. (2009). A green supplier selection model for hightech industry. Expert Systems with Applications, 36(4), 7917-7927.

Leung, L. C., \& Cao, D. (2000). On consistency and ranking of alternatives in fuzzy AHP. European Journal of Operational Research, 124(1), 102-113.

Lin, C.-J., \& Wu, W.-W. (2008). A causal analytical method for group decision-making under fuzzy environment. Expert Systems with Applications, 34(1), 205-213.

Lin, K.-m., \& Lin, C.-w. (2008). Cognition map of experiential marketing strategy for hot spring hotels in Taiwan using the DEMATEL method. Paper presented at the Natural Computation, 2008. ICNC'08. Fourth International Conference on.

Lin, R.-H. (2012). An integrated model for supplier selection under a fuzzy situation. International Journal of Production Economics, 138(1), 55-61.

Lin, Y.-H., \& Tseng, M.-L. (2016). Assessing the competitive priorities within sustainable supply chain management under uncertainty. Journal of Cleaner Production, 112, 2133-2144.

Mefford, R. N. (2011). The Economic Value of a Sustainable Supply Chain. Business and Society Review, 116(1), 109-143.

Mehregan, M. R., Hashemi, S. H., Karimi, A., \& Merikhi, B. (2014). Analysis of interactions among sustainability supplier selection criteria using ISM and fuzzy DEMATEL. International Journal of Applied Decision Sciences, 7(3), 270-294.

Mikhailov, L. (2003). Deriving priorities from fuzzy pairwise comparison judgements. Fuzzy sets and Systems, 134(3), 365-385.

Nishat Faisal, M., Banwet, D. K., \& Shankar, R. (2006). Supply chain risk mitigation: modeling the enablers. Business Process Management Journal, 12(4), 535-552.

Olugu, E. U., \& Wong, K. Y. (2012). An expert fuzzy rule-based system for closed-loop supply chain performance assessment in the automotive industry. Expert Systems with Applications, 39(1), 375384.

Punniyamoorthy, M., Mathiyalagan, P., \& Parthiban, P. (2011). A strategic model using structural equation modeling and fuzzy logic in supplier selection. Expert Systems with Applications, 38(1), 458-474.

Rezaei, J., Ortt, R., \& Scholten, V. (2013). An improved fuzzy preference programming to evaluate entrepreneurship orientation. Applied Soft Computing, 13(5), 2749-2758.

Rabbani, M., Navazi, F., Farrokhi-Asl, H., \& Balali, M. (2018). A sustainable transportation-locationrouting problem with soft time windows for distribution systems. Uncertain Supply Chain Management, 6(3), 229-254.

Saaty, T. L. (1990). How to make a decision: the analytic hierarchy process. European Journal of Operational Research, 48(1), 9-26.

Saaty, T. L., \& Takizawa, M. (1986). Dependence and independence: From linear hierarchies to nonlinear networks. European Journal of Operational Research, 26(2), 229-237.

Seuring, S., \& Müller, M. (2008). From a literature review to a conceptual framework for sustainable supply chain management. Journal of Cleaner Production, 16(15), 1699-1710.

Seuring, S., Sarkis, J., Müller, M., \& Rao, P. (2008). Sustainability and supply chain management-an introduction to the special issue. In: Elsevier.

Shaw, K., Shankar, R., Yadav, S. S., \& Thakur, L. S. (2012). Supplier selection using fuzzy AHP and fuzzy multi-objective linear programming for developing low carbon supply chain. Expert Systems with Applications, 39(9), 8182-8192.

Shen, L., Olfat, L., Govindan, K., Khodaverdi, R., \& Diabat, A. (2013). A fuzzy multi criteria approach for evaluating green supplier's performance in green supply chain with linguistic preferences. Resources, Conservation and Recycling, 74, 170-179. 
Siegel, D. S. (2009). Green management matters only if it yields more green: An economic/strategic perspective. The Academy of Management Perspectives, 5-16.

Tang, C. S., \& Zhou, S. (2012). Research advances in environmentally and socially sustainable operations. European Journal of Operational Research, 223(3), 585-594.

Tsai, W.-H., Chou, W.-C., \& Hsu, W. (2009). The sustainability balanced scorecard as a framework for selecting socially responsible investment: an effective MCDM model. Journal of the Operational Research Society, 60(10), 1396-1410.

Tseng, M.-L., \& Chiu, A. S. (2013). Evaluating firm's green supply chain management in linguistic preferences. Journal of Cleaner Production, 40, 22-31.

Tuzkaya, G., Ozgen, A., Ozgen, D., \& Tuzkaya, U. R. (2009). Environmental performance evaluation of suppliers: A hybrid fuzzy multi-criteria decision approach. International Journal of Environmental Science \& Technology, 6(3), 477-490.

Van Laarhoven, P., \& Pedrycz, W. (1983). A fuzzy extension of Saaty's priority theory. Fuzzy sets and Systems, 11(1-3), 229-241.

Wacker, J. G. (1998). A definition of theory: research guidelines for different theory-building research methods in operations management. Journal of Operations Management, 16(4), 361-385.

Warfield, J. N. (1974). Developing interconnection matrices in structural modeling. IEEE Transactions on Systems, Man, and Cybernetics, 1, 81-87.

Wu, Z., \& Pagell, M. (2011). Balancing priorities: Decision-making in sustainable supply chain management. Journal of operations management, 29(6), 577-590.

Yang, C.-C., \& Chen, B.-S. (2006). Supplier selection using combined analytical hierarchy process and grey relational analysis. Journal of Manufacturing Technology Management, 17(7), 926-941.

Yeh, W.-C., \& Chuang, M.-C. (2011). Using multi-objective genetic algorithm for partner selection in green supply chain problems. Expert Systems with Applications, 38(4), 4244-4253.

Yoon, K., \& Hwang, C.-L. (1981). Multiple attribute decision making: methods and applications: SPRINGER-VERLAG BERLIN AN.

Zadeh, L. A. (1965). Fuzzy sets. Information and control, 8(3), 338-353.

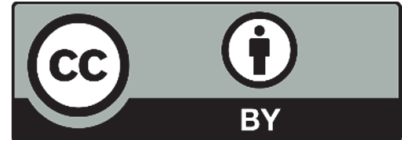

(C) 2018 by the authors; licensee Growing Science, Canada. This is an open access article distributed under the terms and conditions of the Creative Commons Attribution (CC-BY) license (http://creativecommons.org/licenses/by/4.0/). 